(2) Open Access Full Text Article

REVIEW

\title{
Neuropsychological and neurophysiological insights into hoarding disorder
}

This article was published in the following Dove Press journal:

Neuropsychiatric Disease and Treatment

2 April 2015

Number of times this article has been viewed

\section{Jessica R Grisham \\ Peter A Baldwin}

School of Psychology, University of New South Wales, Sydney, Australia

\begin{abstract}
Hoarding disorder (HD) is associated with significant personal impairment in function and constitutes a severe public health burden. Individuals who hoard experience intense distress in discarding a large number of objects, which results in extreme clutter. Research and theory suggest that hoarding may be associated with specific deficits in information processing, particularly in the areas of attention, memory, and executive functioning. There is also growing interest in the neural underpinnings of hoarding behavior. Thus, the primary aim of this review is to summarize the current state of evidence regarding neuropsychological deficits associated with hoarding and review research on its neurophysiological underpinnings. We also outline the prominent theoretical model of hoarding and provide an up-to-date description of empirically based psychological and medical treatment approaches for HD. Finally, we discuss important future avenues for elaborating our model of HD and improving treatment access and outcomes for this disabling disorder.
\end{abstract}

Keywords: hoarding, information processing, neuropsychology, neurophysiology, treatment

\section{Introduction}

Accumulating and storing resources is a primarily adaptive phenomenon that occurs in nonhuman animals ${ }^{1}$ and humans. ${ }^{2}$ At the extreme end of the continuum, some humans collect so many possessions that their homes become uninhabitable and they are unable to function. References to excessive saving date back to medieval literature; the "hoarders" in Dante's Divine Comedy (1995 edition) $)^{3}$ saved up large amounts of money they never spent. Famous early psychologists William James, Erich Fromm, and Sigmund Freud described cases of hoarding and speculated about the underlying causes. ${ }^{4}$ Yet, only over the past 2 decades has hoarding been systematically researched as a discrete psychiatric syndrome.

Modern recognition of hoarding as a disorder began with a research paper published by Frost and Gross. ${ }^{5}$ In their study, the authors developed and evaluated a scale for hoarding, examined associations between hoarding and obsessive-compulsive symptoms, investigated onset and familial factors, and proposed a model of hoarding as an avoidance behavior tied to indecisiveness and perfectionism. ${ }^{5}$ This seminal paper was followed a few years later by the first formal definition: excessive collecting and extreme inability to discard worthless objects. ${ }^{6}$ Since that time, the empirical literature on hoarding and its treatment has exploded, with dozens of research laboratories around the world focused on improving our understanding of this problem. In the current review, we describe the epidemiology of hoarding, address nosological issues related to the disorder, and outline the prominent theoretical model. We then shift to our primary focus, which is to describe the current state of evidence regarding neuropsychological deficits associated with hoarding and possible neurophysiological
Correspondence: Jessica R Grisham School of Psychology, University of New South Wales, Sydney, NSW 2052, Australia

Tel +6I 29385303 |

Email jessicag@unsw.edu.au
Neuropsychiatric Disease and Treatment 2015:1/ 95I-962 (c) (i) (5) 2015 Grisham and Baldwin. This work is published by Dove Medical Press Limited, and licensed under Creative Commons Attribution - Non Commercial (unported, v3.0) License. The full terms of the License are available at http://creativecommons.org/licenses/by-n/3.0/. Non-commercial uses of the work are permitted without any further pew to how to request permission may be found at: http://www.dovepress.com/permissions.php 
underpinnings of the disorder. We conclude with a summary of empirically based psychological and medical treatment approaches for hoarding disorder (HD) and recommendations for future research.

\section{Impact and prevalence}

The profound public health burden associated with HD is now well documented. Individuals who hoard experience impaired daily functioning, social isolation, health problems, and substantial financial cost. ${ }^{7-9}$ Accumulated clutter creates a risk of falling, fire, and sanitation problems that threaten the health, safety, and quality of life of the individuals who hoard and the entire surrounding community. ${ }^{8,10}$ A large Internet survey of individuals with hoarding problems and their family members revealed that hoarding was related to poor physical health, social service involvement, and significant occupational impairment. ${ }^{11}$ Because many individuals who hoard report little distress or insight into the problems caused by their behavior, ${ }^{12}$ hoarding is also associated with high levels of family frustration. ${ }^{9}$ In many cases, attempts by family members and carers to facilitate discarding are met with anxious reluctance or stoic refusal. ${ }^{13}$

Findings from recent epidemiological studies suggest that hoarding problems are more prevalent in the community than was once thought. Data from the Baltimore Epidemiologic Catchment Area Follow-up Survey that used questions from the Personality Disorders section of the Diagnostic and Statistical Manual of Mental Disorders, Fourth Edition (DSM-IV), which defines hoarding as "unable to discard worn-out or worthless objects even when they have no sentimental value," suggested a weighted prevalence rate of 5.3\% for pathological hoarding. ${ }^{14}$ Interviewers thus asked participants: "Do you find it almost impossible to throw out worn-out or worthless things? If so, is that true even when they don't have any sentimental value? Give me some examples. Is this a problem for you or for others? If so, tell me about it." Thus, this survey queried difficulty discarding and interference of hoarding symptoms but failed to confirm hoarding with established measures of the disorder that assess other key facets of hoarding, such as excessive acquisition, reasons for saving, and degree of clutter.

Although data from the National Comorbidity Survey Replication indicated that $14 \%$ of the sample reported hoarding obsessions or compulsions, ${ }^{15}$ this finding is also difficult to interpret because it is unclear whether the hoarding symptoms met clinical criteria. Hoarding was assessed in the context of obsessive-compulsive disorder (OCD) and interviewers asked about specific obsessions (defined as "unpleasant thoughts, images, or impulses") and compulsions ("repeated behaviors or mental acts that you felt compelled to do"), including hoard- ing "obsessions" and "compulsions." It was therefore unclear whether the clinical severity assessment referred to the hoarding symptoms themselves versus other OCD symptoms.

Four studies have used well-established definitions and validated assessments. ${ }^{16-19}$ Across these studies, the prevalence of hoarding ranged from $2.3 \%$ to $6 \%$. These studies also indicated that the presence of hoarding does not vary by sex, although it is likely that more women seek treatment for the problem. Research also suggests that the prevalence of hoarding increases with age. Samuels et $\mathrm{al}^{14}$ reported that hoarding was almost three times more prevalent in individuals over the age of 54 years than it was in individuals aged 34-44 years. This finding reflects the fact that, without intervention, hoarding is a chronic disorder that worsens with age. ${ }^{20}$

\section{Diagnosis and classification}

Hoarding was listed in the text revision of the DSM-IV

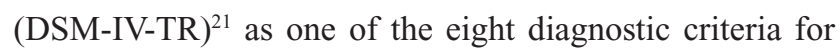
obsessive-compulsive personality disorder (OCPD). Subsequent research, however, established fairly conclusively that hoarding is no more associated with OCPD than it is with other Axis II disorders. ${ }^{22,23}$ Hoarding also has been conceptualized in research and clinical practice as a symptom or subtype of OCD, partially due to the observation that some OCD patients display hoarding symptoms. ${ }^{24}$ Rates of hoarding symptoms in OCD samples range from $18 \%$ to $42 \% .{ }^{25-27}$ Over time, however, substantial evidence accumulated showing that hoarding is distinct from OCD in meaningful ways. ${ }^{23,28,29}$ Patients who hoard, compared to other OCD patients, were found to have different functional neuroimaging profiles, to have distinct clinical features, and to respond differently to treatment. ${ }^{30,31}$ In addition to key distinctions between hoarding and $\mathrm{OCD}$, it is important to note evidence that hoarding behavior occurs secondary to other medical and mental disorders, including schizophrenia, dementia and Alzheimer's disease, and pervasive developmental disorders. ${ }^{32}$

In response to the accumulated findings regarding the distinctiveness of hoarding from OCPD and OCD, HD is defined as a new disorder in the obsessive-compulsive and related disorders section of the fifth edition of the DSM (DSM-5). ${ }^{33}$ The DSM-5 criteria for HD include persistent difficulties in discarding a large number of objects due to a need to save them and distress associated with discarding, clutter that prevents the normal use of living quarters, and significant distress or impairment in functioning caused by hoarding. ${ }^{31}$ As with other disorders, the DSM-5 criteria also specify that the hoarding cannot be attributable to another medical condition (eg, brain injury) or better explained by the symptoms of another mental disorder (eg, delusions in 
schizophrenia). HD has two specifiers in DSM-5. The first, Excessive Acquisition, may indicate individuals who also engage in excessive collecting, buying, or stealing. The second, Insight, reflects the fact that some individuals with HD fail to recognize that they have a problem. ${ }^{33}$

Following initial ambiguity regarding the classification of hoarding behavior, the recent inclusion of HD in DSM-5 as a discrete disorder has been a critical step forward for researchers, clinicians, and individuals with hoarding problems. This new, empirically derived diagnostic category has already begun to facilitate research on hoarding as its own entity, rather than as part of another disorder such as OCD or OCPD. For example, treatment trials have recruited individuals with $\mathrm{HD}$ as a primary diagnosis, rather than examining them as a subset of individuals receiving treatment for OCD. Thus, the independent classification of HD has positively affected public recognition and understanding of the disorder and fueled additional efforts to further develop and refine specific treatments for HD.

\section{A cognitive-behavioral model}

Steketee and Frost ${ }^{34}$ proposed the most widely cited multidimensional model to explain the core manifestations of hoarding (acquiring, clutter, and difficulty discarding). According to their model, hoarding develops as a result of conditioned emotional responses associated with certain thoughts and beliefs about possessions. Individuals fail to discard possessions in order to avoid the anxiety associated with discarding and decision making, whereas positive emotions associated with possessions facilitate acquiring and saving. Frost et $\mathrm{al}^{6,34}$ proposed that three primary factors contribute to hoarding behavior: 1) beliefs about and emotional attachment to possessions, 2) avoidance behaviors that develop as a result of the emotional distress associated with discarding possessions, and 3 ) information-processing deficits in the areas of attention, categorization, memory, and decision making (Figure 1).

Research and clinical observation converge to suggest that hoarding behavior in HD serves to both avoid distress and bring comfort, probably maintaining the disorder through simultaneous positive and negative reinforcement. ${ }^{12}$ Studies examining associations between hoarding and emotion and mood have linked poor emotional regulation, high depression comorbidity, and low distress tolerance with excessive acquiring and difficulties discarding. ${ }^{35-39}$ Although this evidence supports the broad proposition that hoarding behaviors may be driven by difficult emotions, the mechanisms by which some components of the current model contribute to hoarding behaviors are unclear.

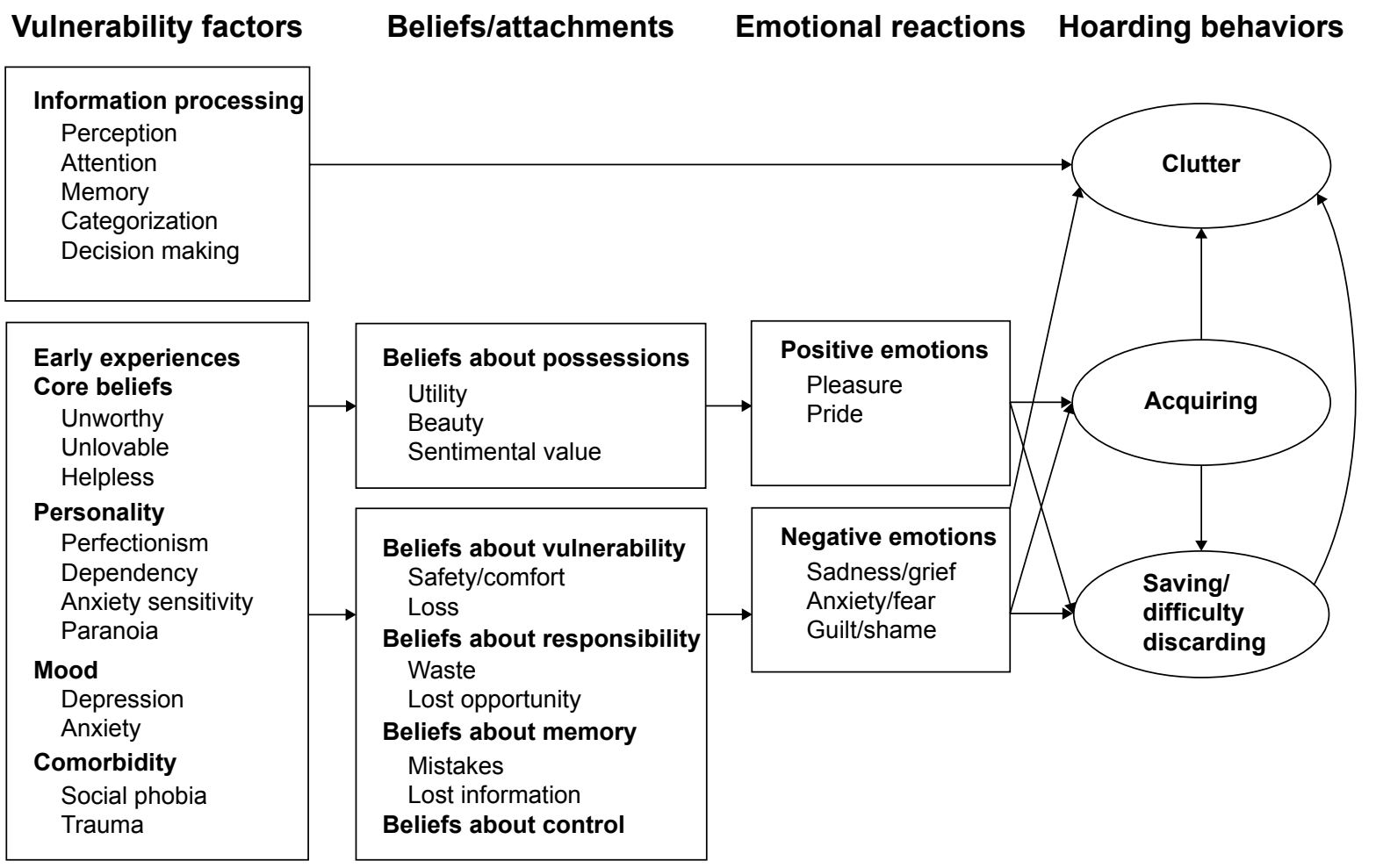

Figure I A cognitive-behavioral model of hoarding disorder.

Note: Copyright @ 2006 . Cambridge University Press. Reproduced from Steketee G, Frost RO. Compulsive Hoarding and Acquiring: Therapist Guide (Treatments That Work). New York: Cambridge University Press; 2006. ${ }^{34}$ 
To further clarify the model, research could examine the direct and indirect effects of psychological vulnerabilities (proposed early in the model) on beliefs, emotions, and hoarding behavior. Indeed, direct remediation of neuropsychological vulnerabilities appears to reduce hoarding symptoms, suggesting that an understanding of underlying mechanisms may facilitate treatment. ${ }^{40,41}$ Future lines of empirical enquiry could examine if low distress tolerance indirectly exacerbates hoarding behavior, potentially increasing cognitive behavioural therapy (CBT) efficacy through adjunctive distress tolerance training. Such refinements to the CBT model may help make treatment more efficient and effective.

\section{Neuropsychological research}

A rapidly growing body of research has focused on evaluating and clarifying the cognitive processing problems proposed in Steketee and Frost's ${ }^{34}$ model. Clinical anecdotes suggested that it was likely that cognitive deficits played some role in the onset and maintenance of hoarding symptoms. ${ }^{42}$ Individuals with clinically significant hoarding symptoms are often easily distracted and require extensive prompting to stay focused on a particular task. ${ }^{43}$ The field has made significant progress in examining these potential deficits with standardized neuropsychological tests and laboratory tasks, ${ }^{44-47}$ but inconsistencies remain regarding the exact profile of the deficits associated with HD. Better understanding of the specific nature of these deficits has critical implications for our understanding of HD and its clinical management. We will briefly review the extant literature on neurocognitive deficits associated with hoarding, which have focused primarily on problems with attention, memory, and executive functioning.

\section{Attention}

Clinicians and researchers have long reported that individuals with hoarding are very distractible, which interferes with their ability both to organize and manage clutter and to stay on task during exposure. ${ }^{43,48}$ Confirming this observation, participants with clinically significant hoarding reported increased symptoms of adult attention deficit hyperactivity disorder (ADHD) in the first study to examine attention in hoarding, ${ }^{43}$ a finding that was replicated in a subsequent study in which individuals with hoarding were contrasted with healthy control participants and a mixed anxiety-and-mooddisorder clinical comparison group. ${ }^{45}$ Other studies found that significantly more patients with OCD with hoarding met diagnostic criteria for ADHD than OCD patients without hoarding. ${ }^{49,50}$ Several studies have also used laboratory-based neuropsychological tests of attention to compare individuals with hoarding difficulties to clinical and nonclinical control groups. Generally, these studies have found that relative to control participants, hoarding participants have some difficulties with sustained and spatial attention..$^{45,47}$ Collectively, these studies appear to confirm that attention deficits are an important feature of hoarding, although the specific nature of the attention problems remains to be fully clarified..$^{51}$

\section{Memory}

Individuals with hoarding problems often report a strong need to keep their possessions in sight in order to avoid forgetting them. ${ }^{52}$ It is thus unsurprising that there is some evidence for biased memory beliefs, as well as verbal and visual memory deficits. Steketee et a $\mathrm{l}^{52}$ found that concern about memory was one of the strongest predictors of hoarding behavior, even after controlling for relevant covariates. Moreover, Hartl et $\mathrm{l}^{53}$ compared participants with clinical hoarding symptoms with healthy control participants on both self-report measures about memory beliefs as well as laboratory-based tests of memory. They found that individuals with clinical hoarding symptoms reported poorer confidence in their memories and overestimated the negative consequences of forgetting. With respect to laboratory tests of memory, Hartl et $\mathrm{al}^{53}$ found that hoarding group members were impaired in delayed recall and copy organization on the Rey-Osterrieth Complex Figure Test. ${ }^{54}$ They also reported that hoarding participants had greater difficulty retaining verbal information over time on the California Verbal Learning Test (CVLT). ${ }^{55}$ However, a second investigation by Tolin et $\mathrm{a}^{47}$ found that HD participants were not impaired on the CVLT relative to OCD patients or healthy control participants. Overall, there is reasonable evidence that hoarding is associated with biased memory and less clear evidence for deficits in verbal and visual memory.

\section{Executive functioning}

Deficits in executive functioning marked by inhibition, planning, and decision-making difficulties may limit the ability of individuals with hoarding problems to discard and organize their possessions. Impaired executive functioning may also underlie poor self-regulation in $\mathrm{HD}$, leading to interpersonal deficits and poor self-care. Compared to other OCD patients, individuals with clinically significant hoarding have been found to have more difficulty initiating and completing tasks and problems with indecision. ${ }^{31}$ Although this behavior may partially reflect task-related anxiety, hoarding patients 
report difficulties with planning and executing complex, goal-directed motor responses and controlling interference. ${ }^{45}$ These problems may reflect impaired self-regulation: an inability to suppress responses evoked by the environment (acquisition and saving), as well as problems sustaining motivation to carry through with tasks (difficulty discarding). With respect to laboratory studies, one study found that OCD patients with hoarding experienced impaired decision-making on the Iowa Gambling Task (IGT) ${ }^{56}$ relative to nonhoarding OCD patients $;{ }^{57}$ however, other studies have not found these deficits on the IGT. ${ }^{45,47,58}$ The discrepancy among studies is probably due to the use of OCD hoarding samples versus pure hoarding samples. Future research should attempt to reconcile the discrepancy between self-reported and clinically observed difficulties with decision making and the null findings regarding laboratory tests of decision making.

The executive-functioning difficulties proposed to underlie hoarding behavior may be linked to the categorization problems demonstrated by hoarding patients. ${ }^{6,46,59}$ Efficient categorization involves planning, strategizing how to best group objects, and decision making. Early hoarding research suggested that individuals who hoarded created too many small categories, which contributes to the general disorganization and clutter. ${ }^{5}$ Three published studies have investigated potential differences in the way people with hoarding categorize personal and nonpersonal objects. ${ }^{46,60,61}$ In these studies, experimenters asked participants to sort personal and/or nonpersonal items into categories. The primary outcomes comprised time to complete the sorting task, the number of categories created, and distress experienced during the task. Luchian et $\mathrm{al}^{60}$ used a student population and contrasted self-identified "pack rats" with healthy control participants. The "pack rat" group created more piles, took more time to sort, and reported more distress. The other two investigations were conducted with individuals with clinically significant hoarding problems and reported similar findings. Wincze et $\mathrm{al}^{61}$ used a healthy control group and an OCD control group, whereas Grisham et $\mathrm{al}^{46}$ studied a healthy control group and a mixed anxiety-and-mood-disorder control group. Although there were minor discrepancies in the findings of these three studies, overall, they support clinical observations that individuals who hoard exhibit an underinclusive categorization style when sorting their belongings, even relative to nonhoarding clinical participants.

Additional research is necessary to iron out some of the inconsistencies in the literature on information processing difficulties and HD. It is important to note that several studies of information-processing difficulties in hoarding have either not included a clinical comparison group or have included only an OCD comparison group. Further research including appropriate clinical comparison groups will help clarify the specificity of these deficits to hoarding. We must also consider the possibility that hoarding emerges as a result of the compounding effects of several deficits acting in concert. ${ }^{62}$ Finally, an important future research direction is to evaluate whether any of these hoarding-related deficits may be ameliorated by the types of cognitive rehabilitation approaches that have been effective for individuals with other psychiatric disorders characterized by neuropsychological deficits, such as schizophrenia. ${ }^{46,60,61}$ Indeed, two studies thus far have investigated the utility of cognitive rehabilitation or cognitive remediation for deficits associated with hoarding. ${ }^{40,41} \mathrm{We}$ describe both of these studies in the "Treatment approaches" section.

\section{Neurophysiology of hoarding}

Findings on neuropsychological deficits in hoarding should be viewed in conjunction with a related line of inquiry examining the possible neurophysiological underpinnings of hoarding. In this section, we review data from functional magnetic resonance imaging (fMRI), positron emission tomography (PET), and electroencephalography that suggest that hoarding behavior is associated with several specific patterns of neural dysfunction. This research focuses primarily on two regions of the brain: the anterior cingulate cortex (ACC) and associated areas, and the precentral and superior frontal gyri. We review the findings on each of these regions in turn.

\section{Dysfunction in the ACC and associated areas}

Most reliably, hoarding individuals exhibit dysfunction in the ACC and associated frontal and medial areas. The dorsal ACC, with connections to medial prefrontal structures, is thought to be involved in decision making, error monitoring, and reward-based learning. The ventral ACC, with connections to limbic structures, is thought to aid in assigning emotional and motivational salience to stimuli and experiences. ${ }^{63}$ It is unsurprising that HD, which is characterized by the inability to make decisions due to error vigilance and overwhelming emotions, might be associated with dysfunction in these regions.

Structural and resting functional examinations of the ACC in individuals with clinically significant hoarding differentiate them both from other clinical individuals and from healthy individuals. Importantly, a review of brain damage 
sequelae found that lesions most associated with suddenonset hoarding after trauma were in the medial prefrontal regions adjacent to the ACC. ${ }^{64}$ A PET examination of hoarding and nonhoarding $\mathrm{OCD}$ individuals revealed that resting ACC activation in hoarding OCD individuals was below that of both healthy controls and nonhoarding OCD individuals and that hoarding symptom severity negatively correlated with ACC activity across all OCD individuals. ${ }^{65}$

To parse hoarding-specific functions from other ACC activities, event-related fMRI studies have examined neural activation in individuals with clinically significant hoarding across three object-related decision-making paradigms: imaginal decisions, virtual decisions, and in vivo decisions. During in vivo discarding of novel objects, ACC activation was significantly lower in hoarding individuals than in healthy individuals and nonhoarding OCD individuals, ${ }^{66}$ and during imaginal discarding of novel objects, hoardingrelated distress correlated negatively with dorsal ACC and orbitofrontal cortex activation. ${ }^{67}$ This suggests that when making decisions about new and unowned objects, the ACC in hoarding individuals is relatively unresponsive.

However, when hoarding individuals are asked to discard objects they do own, the pattern appears to reverse. During decisions about possessions, activation of ACC and insula was significantly higher in hoarding individuals, both during virtual acquiring ${ }^{68}$ and in vivo discarding. ${ }^{66}$ Moreover, one in vivo decision-making study found that ACC activity became even greater on trials where HD individuals refused to discard, in addition to trials in which possessions were successfully discarded. ${ }^{69}$ These data provide evidence for a distinct, dichotomous pattern of ACC and insula activity in HD individuals, the activity being sensitive to object ownership, and may provide some explanation for the fear of erroneous discarding.

Event-related potential (ERP) studies have provided additional evidence for the role of the ACC in HD by examining the error-related negativity (ERN), an ERP component originating from the ACC, originally thought to index error detection activity ${ }^{70}$ and shown to be sensitive to emotion. ${ }^{71,72}$ A meta-analysis of ERP studies compared the ERN amplitude across hoarding and nonhoarding OCD individuals. Despite methodological heterogeneity and limited statistical power, a trend for an enhanced (high amplitude) ERN in hoarding versus nonhoarding OCD individuals approached significance. More broadly, the study found that an enhanced ERN in OCD individuals was associated with avoidant behavior on probabilistic learning tasks. ${ }^{73}$ This is consistent with observations that HD individuals hastily acquire and avoid discarding through fear of error. ${ }^{5}$
Contrary to the results of Matthews et $\mathrm{al}^{73}$ a recent examination of ERN amplitude in an OCD sample found an enhanced ERN in low-hoarding individuals, relative to highhoarding individuals. ${ }^{74}$ This difference may simply reflect the possession-irrelevant nature of the task. Interestingly, the same study found that high-hoarding individuals displayed an enhanced ERN, relative to healthy individuals. This difference somewhat contradicts the low ACC activity in HD individuals relative to controls found on similar tasks. ${ }^{75}$ This apparent contradiction may be due to differences in methodology or hoarding psychometrics; however, replication of this result could help elucidate the role of the ACC in hoarding, in particular, by examining if such an effect is driven by differential activation of dorsal and ventral ACC regions during object-related decision making. Such an examination may implicate the ACC in unhelpful error monitoring, poor emotion regulation, or both.

Finally, despite robust evidence identifying the ACC as the origin of the ERN, ${ }^{76}$ comparisons across these psychophysiological methodologies should be made with caution. Equating ERN amplitude to hemodynamic measures from fMRI data should be enhanced by concurrent localized measures of electromagnetic current density (eg, low-resolution brain electromagnetic tomography) $)^{77}$ before firmer conclusions are drawn.

\section{Dysfunction in the precentral and superior frontal gyri}

In addition to the intriguing findings regarding the role of the ACC, fMRI data suggest that hoarding may also be related to dysfunction in the precentral gyrus and superior frontal gyrus, brain regions involved in motor control and complex behavior, respectively. The pattern of precentral activation also appears sensitive to object ownership; however, this is somewhat less consistent across studies than the pattern observed in the ACC.

In a sample of OCD participants who engaged in imaginal discarding of novel objects, hoarding-related anxiety positively correlated with left precentral gyrus activation, and hoarding individuals showed increased left precentral gyrus and superior frontal gyrus activation compared to nonhoarding individuals. ${ }^{78}$ During in vivo decision making about novel objects, hoarding individuals displayed precentral gyrus hyperactivity during acquiring and superior frontal gyrus hyperactivity during discarding, with both regions normalizing to level of healthy individuals after CBT. ${ }^{68}$ Additionally, a more recent study found that during high-conflict Go/No-Go task, successful response inhibition in HD individuals was associated with greater right precentral 
gyrus activation, compared with nonhoarding OCD individuals. $^{75}$

Similar to patterns of ACC activity, precentral and superior frontal activation appears to differ between successful discarding of possessions and refusal to discard in hoarding individuals. During a study involving in vivo discarding of possessions, hoarding severity negatively correlated with right precentral activation in HD individuals. However, HD individuals displayed greater activation in the precentral gyrus when refusing to discard, compared to trials in which possessions were discarded. Additionally, HD individuals showed lower left superior frontal activation from baseline when discarding possessions than did healthy individuals. ${ }^{69}$

This pattern is not entirely consistent with previous data that suggest that greater precentral activation is associated with acquiring novel objects, rather than possessions. ${ }^{68}$ Despite this inconsistency, it is compelling that a pattern of relatively exaggerated neural response in both the ACC and the precentral gyrus in hoarding individuals occurs during decisions that most closely reflect the clinical presentation of hoarding behavior: refusal to part with possessions. This pattern may reflect a neural process that underpins discarding difficulties in HD and warrants further investigation.

Taken together, current neurophysiological data suggest that hoarding behavior could be partly driven by dysfunction in frontal and medial regions associated with decision making, emotion, and motor control. A dichotomous pattern of ACC and insula response moderated by object possession has emerged across several studies, as has a somewhat less-defined pattern of dysfunction in the precentral and superior frontal gyri. ${ }^{66-69,78}$ Although ACC hypoactivity during discarding decisions about novel objects may reflect an emotional distance for unendowed objects, ACC hyperactivity during decisions about possessions may reflect excessive emotional salience attached to possessions and hypervigilance to erroneous discarding. The ACC has been shown to be particularly sensitive to loss after error, ${ }^{79}$ and ACC activation in HD individuals during discarding of possessions is positively correlated with "not just right" feelings, ${ }^{64}$ a form of error anxiety strongly associated with OCD that drives checking behavior. ${ }^{80}$

The implications for the pattern of activity in the precentral and superior frontal gyri areas are less clear. Activation of the precentral gyrus areas may partially reflect movement during behavioral tasks, although most hoarding studies have used tasks with low motor demands. Precentral and superior frontal activation has also been associated with higherorder cognition and pathology. Excessive precentral gyrus activation during basic, fast-reaction tasks may indicate relatively greater demand of cognitive resources ${ }^{81}$ and has been associated with impulsivity in ADHD adults. ${ }^{82}$ Relatively poor superior frontal gyrus activation may negatively affect self-regulation; ${ }^{83}$ however, this would not explain exaggerated superior frontal gyrus activation during discarding. ${ }^{68}$

Future research could examine precentral and superior frontal activation across behavioral paradigms that manipulate cognitive load and self-regulation in HD samples. If results differ between object-relevant and object-irrelevant tasks, we may better understand how precentral and superior frontal regions contribute to hoarding behavior and cognition.

\section{Treatment approaches}

Along with research aimed at increasing our understanding of hoarding and its etiology, a burgeoning field of clinical research is aimed at developing and evaluating treatment for hoarding. Hoarding has often been described as difficult to treat, partially due to patients' deficient insight into the problem and lack of motivation. ${ }^{84}$ In addition, some studies have found that the presence of hoarding symptoms predicted poor response to gold-standard treatments for OCD, including exposure response prevention and serotonergic medications. ${ }^{85,86}$ Despite these initially discouraging findings, recent research using a specialized CBT for HD has found considerable evidence supporting its efficacy ${ }^{87}$ Moreover, despite early indications that individuals with hoarding respond poorly to medication treatment, recent findings provide some promising evidence for the efficacy of pharmacotherapy approaches to HD, ${ }^{88}$ although more research is needed. We provide an overview of psychological and pharmacological approaches to hoarding in the subsequent section.

\section{Psychological approaches to hoarding}

The most promising psychological approach is CBT specifically adapted for $\mathrm{HD},{ }^{89}$ which targets the four primary problem areas proposed by the cognitive--behavioral model: information-processing deficits, excessive emotional attachment to possessions, behavioral avoidance, and erroneous beliefs about saving and possessions. The treatment includes education about hoarding and improving decision-making skills; development of an organizational system for possessions; graded exposure to the anxiety and emotional distress associated with decision making, discarding, and placing possessions out of sight; and cognitive restructuring regarding beliefs about possessions. ${ }^{34}$ A motivational interviewing 
module ${ }^{90}$ was added to the treatment protocol to address common difficulties with treatment refusal, lack of motivation, and poor insight into hoarding-related problems. ${ }^{91,92}$

Several recent studies have evaluated the efficacy of CBT for hoarding outlined in Steketee and Frost' $\mathrm{s}^{34}$ manual. Using hoarding-specific measures, Tolin et $\mathrm{al}^{92}$ examined outcomes and found reductions in hoarding symptoms, including clutter, excessive acquisition, and difficulty discarding. Following this open trial, Steketee et al ${ }^{87}$ slightly modified the treatment and examined its efficacy in the first randomized controlled trial for hoarding comparing CBT $(n=23)$ to a waitlist condition $(n=23)$. Findings indicated that improvements in hoarding symptoms were greater after 12 sessions of CBT than after a comparable period on the waitlist, with moderately large effect sizes. For the CBT group, the mean score on the primary self-report measure for hoarding symptoms (Saving Inventory Revised [SI-R]) ${ }^{93}$ decreased an average of $15 \%$ from baseline, whereas participants randomized to the waitlist showed virtually no reduction in hoarding symptoms. Results suggest that individuals with HD respond to CBT specifically adapted for HD, although there is scope for improvement with respect to achieving and maintaining subclinical status for HD patients.

In addition, novel interventions have been developed to target information-processing deficits associated with hoarding problems. DiMauro et $\mathrm{al}^{41}$ recently conducted a pilot study evaluating computer-assisted cognitive remediation relative to a relaxation control condition for patients with HD. Results of this study suggested that relative to the control treatment, cognitive remediation produced improvements in attention, but not in memory, executive functioning, or hoarding symptoms. In a similar vein, Ayers et $\mathrm{al}^{40}$ evaluated a novel treatment for geriatric HD, which combined traditional behavioral therapy for hoarding symptoms with cognitive rehabilitation strategies targeting prospective memory, categorization/organization, problem solving, and cognitive flexibility. Results of this open trial were promising with respect to treating HD in older adults. The combined treatment produced response rates $(38.35 \%-40.86 \%)$ that were double the response rates found in the authors' previous trial of cognitive therapy alone for geriatric HD. ${ }^{94}$

Finally, newer treatment modalities for HD have also been examined for efficacy, including a Web-based CBT group intervention ${ }^{95}$ based on Steketee and Frost's manual. ${ }^{89}$ Initial findings of this Web-based program are promising, although additional research is needed. Other novel treatment delivery strategies for hoarding are also being evaluated, including a home-based Webcam trial ${ }^{96}$ and a bibliotherapy-based self-help group. ${ }^{97}$ These pioneering treatment approaches represent an exciting opportunity to expand significantly the number of individuals with HD who receive effective treatment.

\section{Pharmacotherapy for hoarding}

Until recently, hoarding symptoms were thought to be largely resistant to pharmacotherapy. ${ }^{98}$ Within OCD, the presence of hoarding symptoms often predicted poor overall treatment response, including poor response to pharmacotherapy relative to nonhoarding individuals. ${ }^{99}$ Poor pharmacotherapy response may, in part, reflect ACC dysfunction in hoarding, with resting ACC hypoactivity repeatedly associated with relatively poor antidepressant response. ${ }^{100,101}$ However, hoarding is not the only predictor of poor pharmacotherapy response in OCD, nor has this association emerged consistently across all OCD studies. ${ }^{88}$ For example, paroxetine, a selective serotonin reuptake inhibitor, has demonstrated equal efficacy in both hoarding and nonhoarding OCD individuals in the absence of concomitant psychological therapy. ${ }^{86}$

This inconsistency may be due, in part, to poor psychometric specificity in previous research reports, as well as the problems with treatment compliance found in some hoarding treatment studies. Most previous studies of pharmacotherapy for hoarding used OCD measures of hoarding symptoms, ${ }^{102-105}$ such as the Yale-Brown Obsessive-Compulsive Scale, ${ }^{106}$ which probably miss the symptomatological nuances captured by hoarding-specific measures, such as the SI-R. ${ }^{93}$ Additionally, individuals with HD have demonstrated deficits in executive functioning and inconsistent treatment engagement; ${ }^{46,47,107}$ thus, poor pharmacotherapy response may be a function of poor compliance, rather than the efficacy of any one treatment approach.

Recent pharmacotherapy research has incorporated more robust hoarding psychometrics with encouraging results. Serotonin-noradrenaline reuptake inhibitor (SNRI) therapy for individuals with a primary HD diagnosis has led to symptom improvement comparable to that seen in CBT. HD individuals who received extended-release venlafaxine as part of an open-label trial reported mean SI-R reductions of $36 \% .^{108}$ No participants in the open-label trial received concurrent psychological therapy or at-home care.

In some cases, HD individuals receiving extended-release venlafaxine have achieved a $60 \%$ reduction in SI-R scores without additional therapies and have preferred ongoing pharmacotherapy to CBT despite the drug's anticholinergic side effects. ${ }^{88}$ These preliminary findings suggest that SNRI 
therapy alone may be equal in efficacy and acceptability to CBT. Replication should seek to confirm this, and additional research should establish what additive benefits may be offered by combination SNRI/CBT therapy, particularly given that long-term maintenance of psychological improvements in other disorders can depend on CBT. ${ }^{109,110}$

In addition to SNRI therapy, psychostimulants have also been examined in the treatment of HD. Such an approach may seem unusual in an anxiety context but makes more sense when considering that a proportion of HD individuals also endorse ADHD inattention symptoms ${ }^{36}$ and that inattention may better predict hoarding than other OCD symptoms. ${ }^{111}$ ADHD-symptomatic HD individuals who engaged in a 4-week course of methylphenidate experienced mixed improvements in both ADHD and hoarding symptoms, although gains were modest and unanimous discontinuation of methylphenidate may suggest poor treatment acceptability. ${ }^{112}$ Further research on the efficacy of psychostimulants in hoarding will better inform their inclusion in any pharmacological treatment regimen.

\section{Conclusion and future recommendations}

Hoarding disorder is a fairly prevalent psychological disorder with a tremendous impact on individuals with the disorder, their families, and the broader community. New recognition and classification of $\mathrm{HD}$ as a discrete disorder have further fueled the surge in research on mechanisms and treatment. These exciting times for hoarding researchers are coupled with ongoing challenges to understand and resolve inconsistencies in key areas of HD research. Despite the growing consensus that individuals with hoarding exhibit some neurocognitive deficits, there remains a pressing need for additional research to clarify the specific nature of these deficits. Ideally, researchers should consider interactions among problem areas of neuropsychological functioning, as well as interactions between negative beliefs about one's memory and cognitive functioning, and actual cognitive difficulties. Mixed findings and failures to replicate findings across neuropsychological studies on hoarding probably reflect differences in research methodology and in the control groups selected, as well as the use of standardized cognitive tasks that could be more tailored to represent hoarding phenomenology. We are similarly building a knowledge base regarding the neurobiological underpinnings of $\mathrm{HD}$, which has thus far focused on abnormal functioning in the anterior cingulate and the precentral and superior frontal gyri. Again, heterogeneity of results in this research probably reflects, in part, the variety of research designs used to study HD. As HD has transitioned from an OCD or OCPD symptom to a distinct disorder, clinical measures have become better able to capture all salient clinical aspects of the disorder and the neural correlates. In addition, analogs of hoarding behavior are becoming better defined so that laboratory tasks increasingly reflect actual hoarding behavior.

On the treatment frontier, empirical evidence suggests new hope for this notoriously difficult-to-treat disorder, particularly with CBT specifically designed for HD and medication therapies (SNRIs). Yet, there is ample scope for treatment innovation and development, possibly including new strategies to address neurocognitive difficulties in hoarding. Alternative treatment modalities, such as support groups and Web-based treatments, are also currently being evaluated and show promising initial findings. Ultimately, efficacious and accessible treatments are critical in order to reduce the substantial social and economic burden associated with HD.

\section{Acknowledgment}

The first author was supported in part by the June Griffith Fellowship from the Faculty of Science of the University of New South Wales.

\section{Disclosure}

The authors report no conflicts of interest in this work.

\section{References}

1. Stephens DW, Brown JS, Ydenberg RC, editors. Foraging: Behavior and Ecology. Chicago: University of Chicago Press; 2007.

2. Bell DE, Raiffa H, Tversky A, editors. Decision Making: Descriptive, Normative, and Prescriptive Interactions. Cambridge: Cambridge University Press; 1988.

3. Alighieri D. The Divine Comedy: Inferno; purgatorio; paradise. New York, NY: Everyman's Library; 1995.

4. Penzel F. Hoarding in history. In: Frost RO, Steketee G, editors. The Oxford Handbook of Hoarding and Acquiring. New York: Oxford University Press; 2014:6.

5. Frost RO, Gross RC. The hoarding of possessions. Behav Res Ther. 1993;31:367-381.

6. Frost RO, Hartl TL. A cognitive behavioral model of compulsive hoarding. Behav Res Ther. 1996;34:341-350.

7. Frost RO, Hristova V, Steketee G, Tolin DF. Activities of daily living scale in hoarding disorder. J Obsessive Compuls Relat Disord. 2013; 2(2):85-90.

8. Frost RO, Steketee GS, Williams L. Hoarding: a community health problem. Health Soc Care Community. 2000;8:229-234.

9. Tolin DF, Frost RO, Steketee G, Fitch KE. Family burden of compulsive hoarding: results of an internet survey. Behav Res Ther. 2008;46(3): 334-344.

10. Lucini G. An Analysis of Fire Incidents Involving Hoarding Households. Worcester, MA: WPI; 2009:1-98.

11. Tolin DF, Frost RO, Steketee G, Gray KD, Fitch KE. The economic and social burden of compulsive hoarding. Psychiatry Res. 2008;160(2): 200-211. 
12. Steketee G, Frost R. Compulsive hoarding: current status of the research. Clin Psychol Rev. 2003;23(7):905-927.

13. Frost RO, Steketee G, Tolin DF. Diagnosis and assessment of hoarding disorder. Annu Rev Clin Psychol. 2012;8(1):219-242.

14. Samuels JF, Bienvenu OJ, Grados MA, et al. Prevalence and correlates of hoarding behavior in a community-based sample. Behav Res Ther. 2008;46(7):836-844.

15. Ruscio AM, Stein DJ, Chiu WT, Kessler RC. The epidemiology of obsessive-compulsive disorder in the national comorbidity survey replication. Mol Psychiatry. 2010;15:53-63.

16. Bulli F, Melli G, Carraresi C, Stopani E, Pertusa A, Frost RO. Hoarding behaviour in an Italian non-clinical sample. Behav Cogn Psychother. 2013;42(03):297-311.

17. Iervolino AC, Perroud N, Fullana MA, et al. Prevalence and heritability of compulsive hoarding: a twin study. Am J Psychiatry. 2009; 166(10):1156-1161.

18. Mueller A, Mitchell JE, Crosby RD, Glaesmer H, De Zwaan M. The prevalence of compulsive hoarding and its association with compulsive buying in a German population-based sample. Behav Res Ther. 2009;47: 705-709.

19. Timpano KR, Exner C, Glaesmer H, et al. The epidemiology of the proposed DSM-5 hoarding disorder. J Clin Psychiatry. 2011;72(06): 780-786.

20. Grisham JR, Frost RO, Steketee G, Kim H-J, Hood S. Age of onset of compulsive hoarding. J Anxiety Disord. 2006;20(5):675-686.

21. American Psychiatric Association. Diagnostic and Statistical Manual of Mental Disorders DSM-IV-TR Fourth Edition (Text Revision). Arlington, VA: American Psychiatric Association; 2000.

22. Pertusa A, Fullana MA, Singh S, Alonso P, Menchon JM, Mataix-Cols D. Compulsive hoarding: OCD symptom, distinct clinical syndrome, or both? Am J Psychiatry. 2008;165(10):1289-1298.

23. Wu KD, Watson D. Hoarding and its relation to obsessive-compulsive disorder. Behav Res Ther. 2005;43(7):897-921.

24. Mataix-Cols D, Frost RO, Pertusa A, et al. Hoarding disorder: a new diagnosis for DSM-V? Depress Anxiety. 2010;27(6):556-572.

25. Rasmussen SA, Eisen JL. The epidemiology and differential diagnosis of obsessive compulsive disorder. J Clin Psychiatry. 1992;53: 4-10.

26. Samuels JF, Bienvenu OJ 3rd, Riddle MA, et al. Hoarding in obsessivecompulsive disorder: results from a case-control study. Behav Res Ther. 2002;40:517-528.

27. Wheaton M, Timpano KR, Holland LaSalle-Ricci V, Murphy D. Characterizing the hoarding phenotype in individuals with OCD: associations with comorbidity, severity and gender. $J$ Anxiety Disord. 2008;22:243-252.

28. Abramowitz JS, Wheaton MG, Storch EA. The status of hoarding as a symptom of obsessive-compulsive disorder. Behav Res Ther. 2008; 46(9):1026-1033.

29. Grisham JR, Brown TA, Liverant GI, Campbell-Sills L. The distinctiveness of compulsive hoarding from obsessive-compulsive disorder. J Anxiety Disord. 2005;19(7):767-779.

30. Saxena S, Brody AL, Maidment KM, Baxter LR Jr. Paroxetine treatment of compulsive hoarding. J Psychiatr Res. 2007;41(6):481-487.

31. Samuels JF, Bienvenu OJ 3rd, Pinto A, et al. Hoarding in obsessivecompulsive disorder: results from the OCD collaborative genetics study. Behav Res Ther. 2007;45(4):673-686.

32. Pertusa A, Fonseca A. Hoarding behavior in other disorders. In: Frost RO, Steketee G, editors. The Oxford Handbook of Hoarding and Acquiring. New York: Oxford University Press; 2014.

33. American Psychiatric Association. The Diagnostic and Statistical Manual of Mental Disorders: DSM 5. Washington, DC: American Psychiatric Association; 2013.

34. Steketee G, Frost RO. Compulsive Hoarding and Acquiring: Therapist Guide (Treatments That Work). New York: Cambridge University Press; 2006.

35. Frost RO, Steketee G, Tolin DF. Comorbidity in hoarding disorder. Depress Anxiety. 2011;28(10):876-884.
36. Hall BJ, Tolin DF, Frost RO, Steketee G. An exploration of the comorbid symptoms and clinical correlates of clinically significant hoarding symptoms. Depress Anxiety. 2012;30(1):67-76.

37. Timpano KR, Schmidt NB. The relationship between self-control deficits and hoarding: a multimethod investigation across three samples. J Abnorm Psychol. 2013;122(1):13-25.

38. Timpano KR, Buckner JD, Richey JA, Murphy DL, Schmidt NB. Exploration of anxiety sensitivity and distress tolerance as vulnerability factors for hoarding behaviors. Depress Anxiety. 2009;26(4):343-353.

39. Timpano KR, Keough ME, Traeger L, Schmidt NB. General life stress and hoarding: examining the role of emotional tolerance. Int $J \operatorname{Cogn}$ Ther. 2011;4(3):263-279.

40. Ayers CR, Saxena S, Espejo E, Twamley EW, Granholm E, Wetherell JL. Novel treatment for geriatric hoarding disorder: an open trial of cognitive rehabilitation paired with behavior therapy. Am J Geriatr Psychiatry. 2014;22(3):248-252.

41. DiMauro J, Genova M, Tolin DF, Kurtz MM. Cognitive remediation for neuropsychological impairment in hoarding disorder. A pilot study. J Obsessive Compuls Relat Disord. 2014;3(2):132-138.

42. Gilliam CM, Tolin DF. Compulsive hoarding. In: Hudak D, Dougherty DD, editors. Clinical Obsessive-Compulsive Disorders in Adults and Children. New York: Cambridge University Press; 2011:122.

43. Hartl TL, Duffany S, Allen G, Steketee GS, Frost RO. Relationships among compulsive hoarding, trauma, and attention-deficit/hyperactivity disorder. Behav Res Ther. 2005;43(2):269-276.

44. Lawrence NS, Wooderson S, Mataix-Cols D, David R, Speckens A, Phillips ML. Decision making and set shifting impairments are associated with distinct symptom dimensions in obsessive-compulsive disorder. Neuropsychology. 2006;20(4):409-419.

45. Grisham JR, Brown TA, Savage CR, Steketee G, Barlow DH. Neuropsychological impairment associated with compulsive hoarding. Behav Res Ther. 2007;45(7):1471-1483.

46. Grisham JR, Norberg MM, Williams AD, Certoma SP, Kadib R. Categorization and cognitive deficits in compulsive hoarding. Behav Res Ther. 2010;48(9):866-872.

47. Tolin DF, Villavicencio A, Umbach A, Kurtz MM. Neuropsychological functioning in hoarding disorder. Psychiatry Res. 2011;189(3):413-418.

48. Plimpton EH, Frost RO, Abbey BC, Dorer W. Compulsive hoarding in children: six case studies. Int J Cogn Ther. 2009;2(1):88-104.

49. Sheppard B, Chavira D, Azzam A, et al. ADHD prevalence and association with hoarding behaviors in childhood-onset OCD. Depress Anxiety. 2010;27(7):667-674.

50. Torres AR, Fontenelle LF, Ferrão YA, et al. Clinical features of obsessive-compulsive disorder with hoarding symptoms: a multicenter study. J Psychiatr Res. 2012;46:724-732.

51. Spikman J, Van Zomeren E. Assessment of attention. In: Gurd JM, Kischka U, Marshall J, editors. The Handbook of Clinical Neuropsychology. New York: Oxford University Press; 2010:81-96.

52. Steketee G, Frost RO, Kyrios M. Cognitive aspects of compulsive hoarding. Cognit Ther Res. 2003;27(4):463-479.

53. Hartl TL, Frost RO, Allen GJ, et al. Actual and perceived memory deficits in individuals with compulsive hoarding. Depress Anxiety. 2004;20(2):59-69.

54. Osterrieth PA. Le test de copie d'une figure complexe. [The test of copying a complex figure]. Archives de Psychologie. 1944;30: 206-356.

55. Delis DC, Kramer JH, Kaplan E, Ober BH. The California Verbal Learning Test. San Antonio, TX: Psychological Corporation; 1987.

56. Bechara A, Damasio AR, Damasio H, Anderson SW. Insensitivity to future consequences following damage to human prefrontal cortex. Cognition. 1994;50:7-15.

57. Lawrence NS, Wooderson S, Mataix-Cols D, David R, Speckens A, Phillips ML. Decision making and set shifting impairments are associated with distinct symptom dimensions in obsessive-compulsive disorder. Neuropsychology. 2006;20(4):409-419.

58. Blom RM, Samuels JF, Grados MA, et al. Cognitive functioning in compulsive hoarding. J Anxiety Disord. 2011;25:1139-1144. 
59. Frost RO, Steketee G. Hoarding: clinical aspects and treatment strategies. In: Jenike M, Baer L, Minichiello J, editors. Obsessive-compulsive Disorders Practical Management. 3rd ed. St Louis: Mosby Incorporated; 1998:533-554.

60. Luchian S, McNally R, Hooley J. Cognitive aspects of nonclinical obsessive-compulsive hoarding. Behav Res Ther. 2007;45(7):1657-1662.

61. Wincze JP, Steketee G, Frost RO. Categorization in compulsive hoarding. Behav Res Ther. 2007;45:63-72.

62. Timpano KR, Smith AM, Yang JC, Cek D. Information processing. In: Frost RO, Steketee G, editors. The Oxford Handbook of Hoarding and Acquiring. New York: Oxford University Press; 2014:100.

63. Bush G, Luu P, Posner MI. Cognitive and emotional influences in anterior cingulate cortex. Trends Cogn Sci. 2000;4(6):215-222.

64. Anderson SW, Damasio H, Damasio AR. A neural basis for collecting behaviour in humans. Brain. 2005;128(pt 1):201-212.

65. Saxena S, Brody AL, Maidment KM. Cerebral glucose metabolism in obsessive-compulsive hoarding. Am J Psychiatry. 2004;161(6): 1038-1048.

66. Tolin DF, Stevens MC, Villavicencio AL, et al. Neural mechanisms of decision making in hoarding disorder. Arch Gen Psychiarty. 2012;69: $832-841$.

67. An SK, Mataix-Cols D, Lawrence NS, et al. To discard or not to discard: the neural basis of hoarding symptoms in obsessive-compulsive disorder. Mol Psychiatry. 2009;14(3):318-331.

68. Tolin DF, Stevens MC, Nave A, Villavicencio AL, Morrison S. Neural mechanisms of cognitive behavioral therapy response in hoarding disorder: a pilot study. J Obsessive Compuls Relat Disord. 2012;1(3): 180-188.

69. Tolin DF, Kiehl KA, Worhunsky P, Book GA, Maltby N. An exploratory study of the neural mechanisms of decision making in compulsive hoarding. Psychol Med. 2009;39(02):325-336.

70. Falkenstein M, Hoormann J, Christ S, Hohnsbein J. ERP components on reaction errors and their functional significance: a tutorial. Biol Psychol. 2000;51:87-107.

71. Olvet DM, Hajcak G. The error-related negativity (ERN) and psychopathology: toward an endophenotype. Clin Psychol Rev. 2008;28(8): 1343-1354.

72. Olvet DM, Hajcak G. The error-related negativity relates to sadness following mood induction among individuals with high neuroticism. Soc Cogn Affect Neurosci. 2012;7(3):289-295.

73. Mathews CA, Perez VB, Delucchi KL, Mathalon DH. Error-related negativity in individuals with obsessive-compulsive symptoms: toward an understanding of hoarding behaviors. Biol Psychol. 2012;89(2): 487-494.

74. Riesel A, Kathmann N, Endrass T. Overactive performance monitoring in obsessive-compulsive disorder is independent of symptom expression. Eur Arch Psychiatry Clin Neurosci. 2014;264(8):707-717.

75. Tolin DF, Witt ST, Stevens MC. Hoarding disorder and obsessivecompulsive disorder show different patterns of neural activity during response inhibition. Psychiatry Res. 2014;221(2):142-148.

76. Wessel JR. Error awareness and the error-related negativity: evaluating the first decade of evidence. Front Hum Neurosci. 2013;6:1-16.

77. Pascual-Marqui RD, Michel CM, Lehmann D. Low resolution electromagnetic tomography: a new method for localizing electrical activity in the brain. Int J Psychol. 1994;18:49-65.

78. Mataix-Cols D, Wooderson S, Lawrence N, Brammer MJ, Speckens A, Phillips ML. Distinct neural correlates of washing, checking, and hoarding symptom dimensions in obsessive-compulsive disorder. Arch Gen Psychiarty. 2004;61:564-576.

79. Bush G, Vogt BA, Holmes J, et al. Dorsal anterior cingulate cortex: a role in reward-based decision making. Proc Natl Acad Sci US A. 2002; 99(1):523-528.

80. Coles ME, Frost RO, Heimberg RG, Rhéaume J. "Not just right experiences": perfectionism, obsessive-compulsive features and general psychopathology. Behav Res Ther. 2003;41(6):681-700.

81. Rypma B, Berger JS, Prabhakaran V, et al. Neural correlates of cognitive efficiency. Neuroimage. 2006;33(3):969-979.
82. Ding WN, Sun JH, Sun YW, et al. Trait impulsivity and impaired prefrontal impulse inhibition function in adolescents with internet gaming addiction revealed by a Go/No-Go fMRI study. Behav Brain Funct. 2014;10(1):1-9.

83. Goldberg II, Harel M, Malach R. When the brain loses its self: prefrontal inactivation during sensorimotor processing. Neuron. 2006;50(2):329-339.

84. Steketee G, Frost RO. Stuff: Compulsive Hoarding and the Meaning of Things. New York: Houghton Mifflin Harcourt; 2010.

85. Abramowitz JS, Franklin ME, Schwartz SA, Furr JM. Symptompresentation and outcome of cognitive-behavioral therapy for obsessive-compulsive disorder. J Consult Clin Psychol. 2003;71(6):1049-1057.

86. Rufer M, Fricke S, Moritz S, Kloss M, Hand I. Symptom dimensions in obsessive-compulsive disorder: prediction of cognitive-behavior therapy outcome. Acta Psychiatr Scand. 2006;113(5):440-446.

87. Steketee G, Frost RO, Tolin DF, Rasmussen J, Brown TA. Waitlistcontrolled trial of cognitive behavior therapy for hoarding disorder. Depress Anxiety. 2010;27(5):476-484.

88. Saxena S. Pharmacotherapy of compulsive hoarding. J Clin Psychol. 2011;67(5):477-484

89. Steketee GS, Frost RO. Compulsive Hoarding and Acquiring: Therapist Guide. USA: Oxford University Press; 2006.

90. Miller WR, Rollnick S. Motivational Interviewing: Preparing People for Change. 2nd ed. New York: Guilford; 2002.

91. Frost RO, Steketee G, Greene KAI. Cognitive and behavioral treatment of compulsive hoarding. Brief Treat Crisis Interv. 2003;3:323-337.

92. Tolin DF, Frost RO, Steketee G. An open trial of cognitive-behavioral therapy for compulsive hoarding. Behav Res Ther. 2007;45(7): 1461-1470

93. Frost RO, Steketee G, Grisham J. Measurement of compulsive hoarding: saving inventory-revised. Behav Res Ther. 2004;42(10):1163-1182.

94. Ayers CR, Wetherell JL, Golshan S, Saxena S. Cognitive-behavioral therapy for geriatric compulsive hoarding. Behav Res Ther. 2011; 49(10):689-694.

95. Muroff JR, Steketee G, Himle J, Frost R. Delivery of internet treatment for compulsive hoarding (D.I.T.C.H.). Behav Res Ther. 2010;48(1): 79-85.

96. Muroff JR, Steketee G, Frost RO. Cognitive behavioral treatment delivered via webcam. Presented at: The Annual Meeting of the Association for Behavioral and Cognitive Therapies; 2009; New York, NY.

97. Frost RO, Pekareva-Kochergina A, Maxner S. The effectiveness of a biblio-based support group for hoarding disorder. Behav Res Ther. 2011;49(10):628-634.

98. Muroff JR, Bratiotis C, Steketee G. Treatment for hoarding behaviors: a review of the evidence. Clin Soc Work J. 2010;39(4):406-423.

99. Bloch MH, Bartley CA, Zipperer L, et al. Meta-analysis: hoarding symptoms associated with poor treatment outcome in obsessivecompulsive disorder. Mol Psychiatry. 2014;19:1-6.

100. Mayberg HS, Brannan SK, Mahurin RK, et al. Cingulate function in depression: a potential predictor of treatment response. Neuroreport. 1997;8(4):1057-1061.

101. Wu J, Buchsbaum MS, Gillin JC, et al. Prediction of antidepressant effects of sleep deprivation by metabolic rates in the ventral anterior cingulate and medial prefrontal cortex. Am J Psychiatry. 1999;156(8):1149-1158.

102. Black DW, Monahan P, Gable J, Blum N, Clancy G, Baker P. Hoarding and treatment response in 38 nondepressed subjects with obsessivecompulsive disorder. J Clin Psychiatry. 1998;59:420-425.

103. Mataix-Cols D, Rauch SL, Manzo PA, Jenike MA, Baer L. Use of factor-analyzed symptom dimensions to predict outcome with serotonin reuptake inhibitors and placebo in the treatment of obsessive-compulsive disorder. Am J Psychiatry. 1999;156: 1409-1416.

104. Salomoni G, Grassi M, Mosini P, Riva P, Cavedini P, Bellodi L. Artificial neural network model for the prediction of obsessive-compulsive disorder treatment response. J Clin Psychopharmacol. 2009;29(4): 343-349. 
105. Winsberg ME, Cassic KS, Koran LM. Hoarding in obsessivecompulsive disorder: a report of 20 cases. J Clin Psychiatry. 1999;60: 591-597.

106. Goodman WK, Price LH, Rasmussen SA, et al. The Yale-Brown Obsessive Compulsive Scale. I. Development, use and reliability. Arch Gen Psychiarty. 1989;46:1006-1011.

107. Mataix-Cols D, Marks IM, Greist JH, Kobak KA, Baer L. Obsessivecompulsive symptom dimensions as predictors of compliance with and response to behaviour therapy: results from a controlled trial. Psychother Psychosom. 2002;71:255-262.

108. Saxena S, Sumner J. Venlafaxine extended-release treatment of hoarding disorder. Int Clin Psychopharmacol. 2014;29(5):266-273.
109. Fava GA, Rafanelli C, Grandi S, Conti S, Belluardo P. Prevention of recurrent depression with cognitive behavioral therapy. Arch Gen Psychiarty. 1998;55:816-820.

110. Segal ZV, Gemar M, Williams S. Differential cognitive response to a mood challenge following successful cognitive therapy or pharmacotherapy for unipolar depression. J Abnorm Psychol. 1999; 108(1):3-10.

111. Tolin DF, Villavicencio A. Inattention, but not OCD, predicts the core features of hoarding disorder. Behav Res Ther. 2011;49(2):120-125.

112. Rodriguez CI, Bender J Jr, Morrison S. Does extended release methylphenidate help adults with hoarding disorder? A case series. J Clin Psychopharmacol. 2013;33(3):444-447.

\section{Publish your work in this journal}

Neuropsychiatric Disease and Treatment is an international, peerreviewed journal of clinical therapeutics and pharmacology focusing on concise rapid reporting of clinical or pre-clinical studies on a range of neuropsychiatric and neurological disorders. This journal is indexed on PubMed Central, the 'PsycINFO' database and CAS, and is the official journal of The International Neuropsychiatric Association (INA). The manuscript management system is completely online and includes a very quick and fair peer-review system, which is all easy to use. Visit http://www.dovepress.com/testimonials.php to read real quotes from published authors.

\footnotetext{
Submit your manuscript here: http://www.dovepress.com/neuropsychiatric-disease-and-treatment-journal
} 